\title{
Toward a Patient-Centered, Data-Driven Cardiology
}

\author{
Antonio Luiz Ribeiro ${ }^{10}$ and Gláucia Maria Moraes de Oliveira ${ }^{\circledR 0}$ \\ Universidade Federal de Minas Gerais, ${ }^{1}$ Belo Horizonte, MG - Brazil \\ Universidade Federal do Rio de Janeiro, ${ }^{2}$ Rio de Janeiro, RJ - Brazil
}

Beginning in the 1970s and 1980s, the emergence of randomized clinical trials and studies with large cohorts, associated with the development of the methodology for systematic reviews and meta-analyses, triggered a revolution in the way of thinking and performing healthcare practice. Evidence-based medicine (EBM), defined as the integration of the best research evidence with clinical experience and patient values, ${ }^{1}$ has become a new paradigm, orienting medical education and specialized publications. One of the principles of EBM was precisely the primacy of information obtained from randomized clinical trials and meta-analyses, which were placed at the top of an evidence hierarchy, valuing quantitative results more than clinical experience and expert opinion. Indeed, it has always been challenging for EBM to integrate empirical evidence with other types of medical knowledge, such as clinical expertise and pathophysiological rationale, or even with the preferences of individual patients. ${ }^{2}$

The use of EBM in clinical practice also runs into the difficulty of finding robust evidence for all subgroups of clinical situations found in the real world, "gray areas" in which no reliable evidence can be obtained from the scientific literature to guide the physician in caring for his patient. Randomized clinical trials are expensive and generally require large study samples and long-term follow-up. There are several situations without evidence, or situations in which the evidence is inconsistent or of poor quality. ${ }^{3}$

In the last two decades, the use of digital technology has invaded daily life worldwide and radically changed the way people live and relate, with a direct impact on healthcare practice. Public and private information systems and administrative record systems in healthcare practice have become ubiquitous and increasingly complex and complete, storing information ranging from diseases of compulsory notification to reasons for hospitalization and cause of death.

Diagnostic equipment has become digital, and electronic medical records began to accumulate the patients' clinical information, prescribed medications, and laboratory tests. Smartphones and digital devices began tracking physical

\section{Keywords}

Cardiology; Clinical Decision - Making; Patient Centered Care; Evidence-Based Medicine/methods; Access Health Technologies; Artificial Intelligence; Diagnostic Equipment Digital; Machine Learning/trends; Health Manager; Physician Patient Relations.

Mailing Address: Gláucia Maria Moraes de Oliveira •

Universidade Federal do Rio de Janeiro - R. Prof. Rodolpho P. Rocco, 255 - 8 ${ }^{\circ}$. Andar - Sala 6, UFRJ. Postal Code 21941-913, Cidade Universitária, RJ - Brazil E-mail: glauciam@cardiol.br, glauciamoraesoliveira@gmail.com

DOI: 10.5935/abc.20190069 activity or recording an individual's diet, in a myriad of applications and software, including information sharing on social networks. Computational advances also allowed the emergence of bioinformatics, with the attainment of a large volume of genetic information, as well as information about proteins, hormones, and other substances present in the body.

The availability of this huge amount of data and new analytical techniques - big data analytics ${ }^{4}$ - opens up new scientific possibilities promising to bring about a real revolution in healthcare practice. Artificial intelligence (AI) areas, such as machine learning and data mining, allow for interactive interpretation and apprehension of the unstructured information available in large databases, recognizing hidden patterns of combination of information that are not obtained with traditional statistical methods. ${ }^{5}$ Al-based methods are being increasingly applied to cardiology to diagnose combinations of multiple imaging modalities, biobanks, electronic cohorts remote and on-site clinical sensors for monitoring of chronic pathologies, electronic health records, and genomes and other molecular techniques, among others ${ }^{6}$ (Table 1 ).

The complete sequencing of the genome and exome, already available in multiple centers, and the future sequencing of the proteome, transcriptome, and metabolome may lead to the knowledge of biological differences among individuals, contextualizing the observed phenotypes with their molecular characterization, leading to the modulation of treatment for specific targets, with greater safety and precision, in the so-called precision medicine. ${ }^{7}$ This perspective of transformation of how knowledge is generated and applied, from the use of new data sources and analysis methodologies, has the potential to bring a new paradigm to medical and healthcare practice (Table 1). ${ }^{8-13}$

However, the use of this large volume of data by healthcare managers and professionals for planning of actions in healthcare and direct patient care is still a major challenge. Difficulties and risks cannot be underestimated. ${ }^{14,15}$ Studies on $\mathrm{Al}$ are usually based on observational data obtained from administrative databases or medical records, with the potential for different types of biases and confounding factors. The associations obtained rarely meet the criteria of causality, and well-designed and long-running studies will continue to be necessary for proving hypotheses and defining causality. On the other hand, most algorithms used work with the "black box" principle, without allowing the information user to know the reasons why a diagnosis or recommendation was generated, which can be a problem, especially if the algorithms were designed for a different environment than the one that the user's patient is inserted. Issues regarding information ethics, privacy, and security are still far from being resolved. Matters regarding the cost and cost-effectiveness of healthcare $\mathrm{Al}$ projects should be considered early, given 
Table 1 - Examples of recent studies with artificial intelligence (Al) applications implemented in cardiology ${ }^{8.13}$

\begin{tabular}{|c|c|c|}
\hline Article & Publication & Application of Al in cardiology \\
\hline $\begin{array}{l}\text { Machine learning of three-dimensional right ventricular motion } \\
\text { enables outcome prediction in pulmonary hypertension: a } \\
\text { cardiac MR imaging study }\end{array}$ & $\begin{array}{l}\text { Dawes TJW et al. } \\
\text { MR imaging study Radiology } \\
\text { 2017;283(2):381-90 }\end{array}$ & $\begin{array}{c}\text { Evaluation of outcomes in pulmonary arterial hypertension } \\
\text { based on a highly accurate algorithm derived from nuclear } \\
\text { magnetic resonance }\end{array}$ \\
\hline $\begin{array}{l}\text { Differences in repolarization heterogeneity among heart failure } \\
\text { with preserved ejection fraction phenotypic subgroups }{ }^{9}\end{array}$ & $\begin{array}{c}\text { Oskouie SK et al } \\
\text { Am J Cardiol 2017;120(4):601-6 }\end{array}$ & $\begin{array}{l}\text { Identification of phenotypic patterns in heart failure with preserved } \\
\text { ejection fraction and unfavorable prognosis }\end{array}$ \\
\hline $\begin{array}{l}\text { Screening for cardiac contractile dysfunction using an artificial } \\
\text { intelligence-enabled electrocardiogram }\end{array}$ & $\begin{array}{c}\text { Attia Zl } \\
\text { Nat Med. } 2019 \text { Jan;25(1):70-74 }\end{array}$ & $\begin{array}{l}\text { Al applied to electrocardiography for identification of patients with } \\
\text { left ventricular dysfunction }\end{array}$ \\
\hline $\begin{array}{l}\text { Artificial intelligence to predict needs for urgent } \\
\text { revascularization from 12-lead electrocardiography in } \\
\text { emergency patients }^{11}\end{array}$ & $\begin{array}{c}\text { Goto S et al } \\
\text { PLoS ONE 201914(1):e0210103 }\end{array}$ & $\begin{array}{l}\text { Prediction of urgent revascularization in patients with chest pain in } \\
\text { the emergency room }\end{array}$ \\
\hline $\begin{array}{l}\text { Fast and accurate view classification of echocardiograms } \\
\text { using deep learning }\end{array}$ & $\begin{array}{l}\text { Madani, A..et al } \\
\text { NPJ Digit. Med. } 20181,6, .24\end{array}$ & Use of Al for interpretation with good accuracy of echocardiograms \\
\hline $\begin{array}{l}\text { Fully automated echocardiogram interpretation in clinical } \\
\text { practice feasibility and diagnostic accuracy }{ }^{13}\end{array}$ & $\begin{array}{l}\text { Zhang, J. et al. } \\
\text { Circulation } 2018138,1623-35\end{array}$ & $\begin{array}{l}\text { Automated assessment of echocardiographic measurements } \\
\text { comparable to or greater than manual assessment }\end{array}$ \\
\hline
\end{tabular}

Table 2 - Premises to guide the future of artificial intelligence (Al) in medicine

- The patient must be considered to be at the center upon implementation of any new technology.

- The incorporation of these new technologies for diagnosis and treatment should occur after robust validation of their clinical efficacy.

- The use of digital tools and decision algorithms by patients should be another option for those patients who feel empowered.

- Cross-disciplinary training will need to be undertaken involving healthcare professionals, engineers, computer scientists, and bioinformaticians, who will minimize the difficulties of implementing the new technology.

Adapted from Topol EJ ${ }^{16}$

the high expenditures in this sector. Topol, ${ }^{16}$ in a recent review, emphasized the premises that should guide the future application of $\mathrm{Al}$ in healthcare (Table 2). ${ }^{16}$

If greater availability of data and new Al techniques allow for more accurate diagnoses and prognoses, as well as personalized treatments, various aspects of healthcare practice will continue to depend on other dimensions, such as political, economic, and cultural ones, and the ability of healthcare professionals to interact with patients and the community. The issue of unequal access to healthcare is still critical in Brazil and in developing countries, and requires large investments to improve the organization of the healthcare system. Even when healthcare services and evidence-based guidelines are available, for common and relevant conditions such as hypertension and diabetes, the implementation gap is gigantic and best practices are not absorbed by healthcare professionals, or recommended measures are not implemented by patients and their families. The implementation science developed in recent decades, proves to be as important as the data science for the recognition of bottlenecks hindering the complete use of preventive and therapeutic measures ensuring benefit to the patients, who may live more and better, benefiting from all available knowledge. ${ }^{17}$

Thus, personalized medicine and $\mathrm{Al}$ promise to provide a powerful tool for complex and personalized healthcare data management, which will only be effective if used in the context of the art of caring and the doctor-patient relationship, allowing a new paradigm of medicine based on data but focused on the patient. Physicians and healthcare professionals will be responsible for evaluating and learning the new techniques, expanding the resources available to fully benefit the patients, in terms of not only their physical condition, but also their mental and spiritual conditions, minimizing the suffering that results from the process of illness. ${ }^{18}$

\section{References}

1. Sackett DL, Straus SE, Richardson WS, Rosenberg W, Brian Haynes R. Evidence-Based Medicine: How to practice and teach EBM. 2nd ed. London: Churchill Livingstone; 2000.

2. Tonelli MR. Integrating evidence into clinical practice: an alternative to evidence-based approaches. J Eval Clin Pract. 2006;12(3):248-56.
3. Kernick DP. Lies, damned lies, and evidence-based medicine. Lancet.1998;351(9118):1824.

4. Gu D, Li J, Li X, Liang C. Visualizing the knowledge structure and evolution of big data research in healthcare informatics. Int J Med Inform. 2017 Feb;98:22-32. 


\section{Editorial}

5. Shameer K, Johnson KW, Glicksberg BS, Dudley JT, Sengupta PP. Machine learning in cardiovascular medicine: are we there yet? Heart 2018;104(14):1156-64.

6. Johnson KW, Soto JT, Glicksberg BS, Shameer K, Miotto R, Ali M, et al. Artificial Intelligence in Cardiology. J Am Coll Cardiol. 2018;71(23):2668-79.

7. Savoia C, Volpe M, Grassi G, Borghi C, Agabiti Rosei E, Touyz RM. Personalized medicine- a modern approach for the diagnosis and management of hypertension. Clin Sci (Lond). 2017;131(22):2671-85.

8. Dawes TJW, de Marvao A, Shi W, Fletcher T, Watson GMJ, Wharton J, et al. Machine learning of three-dimensional right ventricular motion enables outcome prediction in pulmonary hypertension: a cardiac MR imaging study. Radiology. 2017;283(2):381-90.

9. Oskouie SK, Prenner SB, Shah SJ, Sauer AJ. Differences in repolarization heterogeneity among heart failure with preserved ejection fraction phenotypic subgroups. Am J Cardiol. 2017;120(4):601-6.

10. Attia ZI, Kapa S, Lopez-Jimenez F, McKie PM, Ladewig DJ, Satam G, et al. Screening for cardiac contractile dysfunction using an artificial intelligenceenabled electrocardiogram. Nat Med.2019;25(1):70-4.

11. Goto S, Kimura M, Katsumata Y, Goto S, Kamatani T, Ichihara G, et al. Artificial intelligence to predict needs for urgent revascularization from 12-leads electrocardiography in emergency patients. PLoSONE.201914(1): e0210103.
12. Madani, A, Arnaout R, Mohammad M, Arnaout R. Fast and accurate view classification of echocardiograms using deep learning. NPJ Digit. Med. 2018:1; pii 6.

13. Zhang J, Gajjala S, Agrawal P, Tison GH, Hallock LA, Beussink-Nelson L, et al. Fully automated echocardiogram interpretation in clinical practice feasibility and diagnostic accuracy. Circulation. 2018;138(13):1623-35.

14. Maddox TM, Rumsfeld JS, Payne PRO. Questions for artificial intelligence in health care. JAMA.2019;321(1):31-2.

15. Topol EJ. High-performance medicine: the convergence of human and artificial intelligence. Nat Med. 2019;25(1):44-56.

16. Topol EJ. The Topol Review. An independent report on behalf of the Secretary of State for Health and Social Care. [Internet]. [Accessed in 2019 Feb 17]. Available from: https://topol.hee.nhs.uk/

17. Chan WV, Pearson TA, Bennett GC, Cushman WC, Gaziano TA, Gorman PN, et al. ACC/AHA Special Report: Clinical Implementation Strategies: A Summary of Systematic Reviews by the NHLBI Implementation Science Work Group: A Report of the American College of Cardiology/American Heart Association Task Force on Clinical Practice Guidelines. Circulation. 2017;135(9):e122-e137.

18. Chen $\mathrm{H}$, Asch SM. Machine learning and prediction in medicine - beyond the peak of inflated expectations. N Engl J Med. 2017;376(26):2507-9. 